\title{
The acute effect of budesonide/formoterol in COPD: a multi-slice computed tomography and lung function study
}

\author{
Lieve A. De Backer*, Wim Vos", Jan De Backer", Cedric Van Holsbeke", \\ Samir Vinchurkar ${ }^{\#}$ and Wilfried De Backer*
}

ABSTRACT: The Global Initiative for Chronic Obstructive Lung Disease (GOLD) classification of chronic obstructive pulmonary disease (COPD) does not always match with other clinical disease descriptors such as exacerbation frequency and quality of life, indicating that forced expiratory volume in $1 \mathrm{~s}$ (FEV1) is not a perfect descriptor of the disease. The aim of this study was to find out whether changes in airway geometry after inhalation of the most commonly used inhalation therapy in severe COPD can more adequately be described with an image-based approach than with spirometry.

10 COPD GOLD stage III patients were assessed in a double-blind crossover study. Airway volumes were analysed using segmentation of multi-slice computed tomography (MSCT) images; airway resistance was determined using computational fluid dynamics (CFD).

Distal airway volume significantly increased $(p=0.011)$ in patients $4 \mathrm{~h}$ after receiving a budesonide/formoterol combination from $9.6 \pm 4.67 \mathrm{~cm}^{3}$ to $10.14 \pm 4.81 \mathrm{~cm}^{3}$. Also CFD-determined airway resistance significantly decreased $(\mathrm{p}=0.047)$ from $0.051 \pm 0.021 \mathrm{kPa} \cdot \mathrm{s} \cdot \mathrm{L}^{-1}$ to $0.043 \pm$ $0.019 \mathrm{kPa} \cdot \mathrm{s} \cdot \mathrm{L}^{-1}$. None of the lung function parameters showed a significant change. Only functional residual capacity $(F R C)$ showed a trend to decline $(p=0.056)$. Only the image-based parameters were able to predict the visit at which the combination product was administered.

This study showed that imaging is a sensitive, complementary tool to describe changes in airway structure.

KEYWORDS: Chronic obstructive pulmonary disease, imaging techniques in chronic obstructive pulmonary disease, inhalation treatment, lung function testing

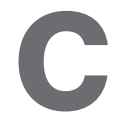
hronic obstructive pulmonary disease (COPD) is characterised by chronic airway inflammation (bronchitis) and the destruction of lung parenchyma in combination with the loss of vascular structures (emphysema). A hallmark of COPD is the relatively irreversible nature of the airway constriction. In clinical practice, patients are diagnosed with COPD if the decrease in forced expiratory volume in $1 \mathrm{~s}$ (FEV1) is not fully reversible after the administration of bronchodilating products and when the ratio between the FEV1 and the forced vital capacity (FVC) remains below $70 \%$. It is, however, possible that a substantial degree of reversibility of bronchoconstriction in COPD can be detected. This reversibility of bronchoconstriction tends to vary over time and with disease severity as well as with the method and product of treatment [1, 2]. It would be interesting to predict this response and categorise patients according to bronchodilating capacity. FEV1 represents the whole of the bronchial tree, so cannot show local bronchodilation, which can be important for the medication to be effective. As COPD is such a heterogeneous disease, bronchodilating capacity is only part of the patient assessment. The severity of COPD is defined by the Global Initiative for Chronic Obstructive Lung Disease (GOLD) guidelines [3] consisting of four categories. Patients are subdivided into these groups based on their post-bronchodilator FEV1 value. Even though FEV1 remains the primary outcome parameter to describe respiratory diseases in clinical studies and practice, only weak correlations have been found between this parameter and patient-reported outcomes such as the St George's Respiratory Questionnaire (SGRQ) [4-7]. The FEV1-based categorisation can still be improved [8]. Today, the standard treatment of COPD includes inhaled corticosteroids (ICS) and short- (SABA) and long- (LABA) acting $\beta_{2}$-agonists. However, the inherent black-box approach of the spirometry parameters in combination with the
AFFILIATIONS

*Dept of Respiratory Medicine, Antwerp University Hospital. and

${ }^{\#}$ FluidDA, Antwerp, Belgium.

CORRESPONDENCE

L.A. De Backer Dept of Respiratory Medicine Antwerp University Hospital Wilrijkstraat 10 2650 Edegem

Antwerp

Belgium

E-mail: lieve.debacker@ua.ac.be

Received:

April 292011

Accepted after revision: Nov 282011

First published online: Dec 192011 
above-mentioned weak clinical correlations often causes difficult and very costly development and registration processes for new compounds targeted at treating COPD [9]. Even in very large clinical trials, the beneficial effect of therapies on FEV1 or even survival is difficult to demonstrate [10-12]. Given the increasing prevalence of COPD [13], the need for new outcome parameters that more adequately describe the influence of inhalation medication on the airway geometry is apparent. These outcome parameters should ideally facilitate development of novel effective therapies that relieve the burden primarily on the patient but also on the social healthcare structure. Within the field of COPD, imaging, and in particular multi-slice computed tomography (MSCT), has emerged as a complementary tool to spirometry and body plethysmography, predominantly to assess the extent of emphysema [14-16]. The severity of emphysema is typically correlated with a decrease in local Hounsfield units $(\mathrm{HU})$, indicating a destruction of pulmonary lung tissue. Recent developments have extended the use of MSCT scans by adding more functionality to the static images by means of airway segmentation and computational fluid dynamics (CFD) [17]. Patient-specific assessments of the airway volume and airflow in the respiratory system can be obtained by solving mathematical flow equations within the segmented airway structures [18]. Several studies have indicated the possible applications of this method and have validated the approach through comparison with in vitro and in vivo data $[19,20]$. The current study used the same approach where patient-specific computer models are constructed based on MSCT images using segmentation principles and flow parameters are derived using CFD. The aim of the present study was to find out whether in GOLD stage III COPD patients, treated with inhalation of routinely used inhalation therapy or placebo, changes in airway structure and function are more adequately described with this new imaging technology than with spirometric data. Fixed combinations were chosen as the study medication to reflect the real-life situation. We also performed a sample size calculation to calculate the number of patients in clinical trials needed when using more sensitive, image-based outcome parameters.

\section{MATERIALS AND METHODS Ethics}

The study was conducted according to all ethical principles. Approval from the ethical committee of Antwerp University Hospital was obtained and all patients gave their informed consent.

\section{Patient population}

In this study 10 COPD patients (six male/four female) were included. All patients were categorised by the GOLD guidelines as GOLD stage III with a mean \pm SD FEV1 of $34.8 \pm 7.7 \%$ predicted. The mean \pm SD age of the patients was $65.1 \pm 3.3 \mathrm{yrs}$ with a mean \pm SD height of $170 \pm 7 \mathrm{~cm}$ and weight of $93 \pm 15 \mathrm{~kg}$.

\section{Study design}

This was a double-blind, placebo-controlled crossover study designed to investigate a number of topics. A first aim was to demonstrate how functional imaging parameters such as changes in airway volumes and CFD-determined resistance can assess changes induced by a combination product compared to placebo. Subsequently these changes could be compared to other lung function parameters. Furthermore a comparison could be made between the combination product and placebo. A final aim of the study was to analyse whether the different outcome parameters could distinguish between placebo and active product. The latter was possible considering the double-blind design of the study.

At baseline (V1), patients received full lung-function testing and a low-dose inspiratory-expiratory MSCT scan. A low-dose computed tomography $(\mathrm{CT})$ scan reduces the radiation by lowering the current and increasing the pitch compared to a normal thoracic CT. Due to the natural contrast between air and the surrounding airway tissue, a significant reduction, up to six-fold, in the radiation dose can be obtained [21]. The lung function tests yielded the following parameters: FEV1, FEV1/FVC and peak expiratory flow (PEF) from the spirometry; and airway resistance (Raw), specific airway resistance (sRaw), functional residual capacity (FRC) and total lung capacity (TLC) from body plethysmography. After the initial tests and scans the patients were randomised to receive either placebo or budesonide/

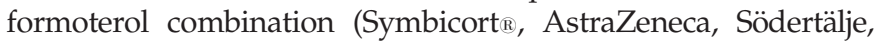
Sweden). In this study a combination product (ICS/LABA) was used as suggested by the GOLD guidelines for the treatment of COPD GOLD stage III patients. The lung function and imaging tests were repeated $4 \mathrm{~h}$ after the administration of the product or placebo (V2). Patients returned to the hospital 1 week later, and the lung function tests were repeated pre-dose (V3). To limit radiation dose, no baseline MSCT scan was taken at this point. Subsequently patients received either the combination product or placebo. Again, $4 \mathrm{~h}$ after the administration of the formulation, both lung function and imaging tests were performed (V4). To limit the radiation dose given to the patient as much as possible a dose-reduction protocol was applied. The natural contrast between the intraluminal air and the surrounding tissue allows for a significant reduction in dose without compromising image quality. The scanner used was a General Electric VCT Lightspeed scanner (GE Healthcare, Chalfont St Giles, UK) with 64 detector rows. The MSCT settings were as follows: tube voltage, $120 \mathrm{kV}$; tube current, between $10 \mathrm{mAs}$ (low-weight patients) and $100 \mathrm{mAs}$ (high-weight patients); noise factor, 28; collimation, $0.625 \mathrm{~mm}$; rotation time, $0.6 \mathrm{~s}$; and pitch factor, 1.375 . The field of view was indicated by the CT technician based on the scout image and was positioned closely around the thorax to optimise in-plane image resolution which was $\sim 0.5 \mathrm{~mm}$. The resulting radiation dose was in the order of $1-2 \mathrm{mSv}$ per scan. Images were reconstructed to a slice thickness of $0.6 \mathrm{~mm}$ to attain near cubic voxels. Respiratory gating was used to ensure the proper lung volume. CT examinations were performed blindly.

\section{Image post-processing}

Post-processing of the MSCT images included segmentation of the airway tree structure and CFD flow simulations. Segmentation can be defined as the grouping of voxels that belong to an anatomical structure (e.g. tracheobronchial tree, lung). This group of voxels or mask can subsequently be used to create a patientspecific three-dimensional model of the anatomical structure under consideration. For this study the focus was placed on the tracheobronchial tree, with HU ranging from -1024 to -824 [20], and in particular the smaller airways starting from the segmental level (generation 2-4). Using state-of-the-art imaging equipment it is possible to distinguish, in the MSCT images, airways with a diameter as low as $1 \mathrm{~mm}$. Smaller airways cannot be further detected since the in-plane resolution of the scanner $(512 \times 512)$ is 
typically not sufficient to distinguish between the intraluminal and the alveolar air. Consequently the analysis was performed on all airways starting from generation 2-4 down to the smallest detectable airways. The DICOM (Digital Imaging and Communications in Medicine) images obtained in this clinical study at the different measurement instances were assessed using the commercially available, US Food and Drug Administration approved, software package MIMICS (Materialise, Leuven, Belgium). The tracheobronchial tree was subsequently segmented using a semiautomatic approach where the central airways up to around generation 4-5 are automatically generated and the smaller branches are added manually. A total of three airway tree models were obtained per patient: the model from V1 was based on prebronchodilation images, the airway constructed at V2 was either after administration of placebo or the combination, and the model based on V4 was again either after administration of placebo or the combination depending on what was used in V2. After segmentation, all models of the same patient were superimposed using a least-squares method. Subsequently all models were trimmed such that the branches extended equally far and a comparison could be made between the different geometries excluding the variability induced by the manual segmentation. The main outcome parameter of the segmentation procedures is the distal airway volume (iVaw) (fig. 1). In addition to the changes in volume, the changes in Raw were determined using CFD (to give $\mathrm{i}$ Raw). CFD is a computer method that provides flow characteristics throughout the entire reconstructed airway model. Flow simulations were performed using Fluent v6.3 (Ansys Inc,

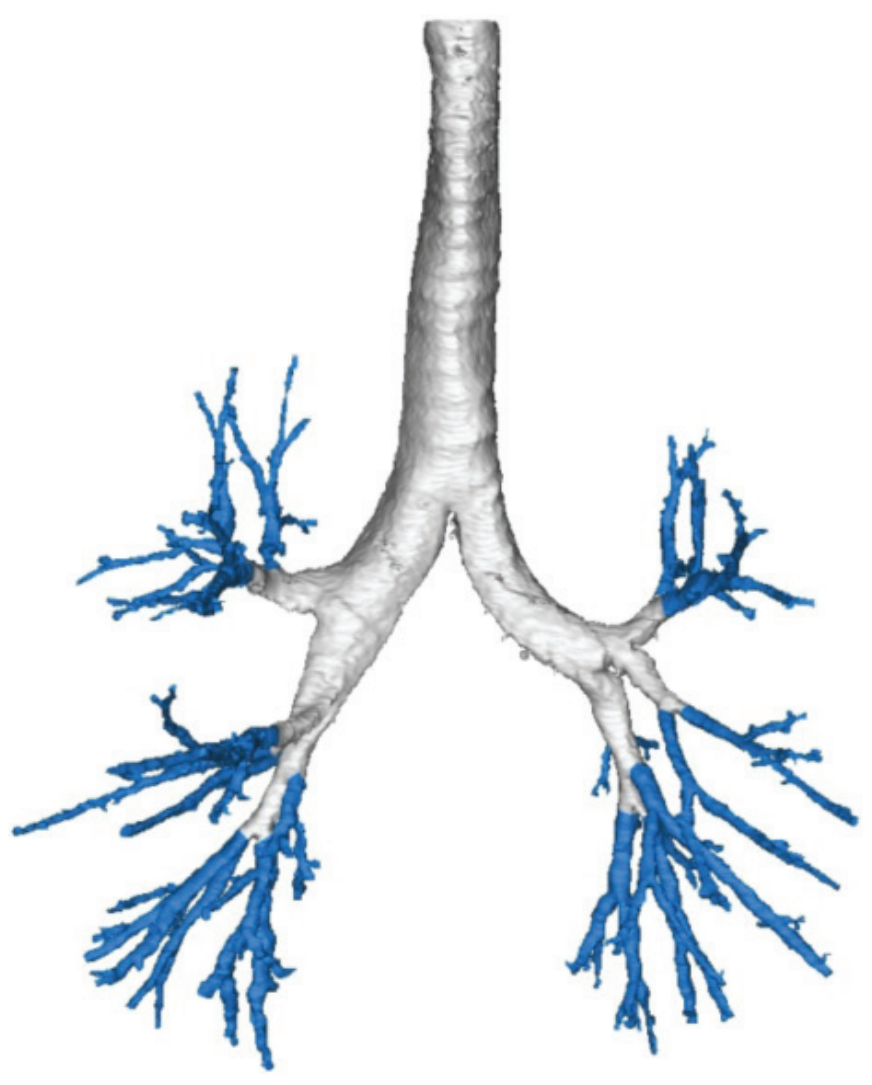

FIGURE 1. Multi-slice computed tomography-based airway model indicating volume of distal airway branches at baseline.
Lebanon, NH, USA), which solved the Reynolds-averaged Navier-Stokes (RANS) equations. Steady flow was considered at $30 \mathrm{~L} \cdot \mathrm{min}^{-1}$. More details on the flow simulation principles can be found in DE BACKER et al. [19]. The CT and CFD analysts were blinded with respect to the randomisation to avoid any bias.

\section{Statistics}

Differences were assessed using the Wilcoxon matched-pairs test. Sample size calculations were performed using power analyses. A p-value $<0.05$ was considered to be statistically significant. Results are presented as mean $\pm \mathrm{SD}$.

\section{RESULTS}

$\mathrm{i} V$ aw significantly increased $(\mathrm{p}=0.011)$ in patients $4 \mathrm{~h}$ after they received budesonide/formoterol in combination (table 1). The distal airway volumes increased from $9.6 \pm 4.67 \mathrm{~cm}^{3}$ to $10.14 \pm 4.81 \mathrm{~cm}^{3}$. The airway resistance decreased from $0.051 \pm$ $0.021 \mathrm{kPa} \cdot \mathrm{s} \cdot \mathrm{L}^{-1}$ to $0.043 \pm 0.019 \mathrm{kPa} \cdot \mathrm{s} \cdot \mathrm{L}^{-1}$. Figure 2 illustrates changes in distal airway volumes after the administration of the placebo and the combination product. No lung function parameter showed a significant change. The FEV1 did increase slightly from $34.8 \pm 7.69 \%$ pred to $35.9 \pm 7.89 \%$ pred but not significantly $(\mathrm{p}=0.34)$. The $\mathrm{sRaw}$ decreased from $5 \pm 2.87 \mathrm{kPa} \cdot \mathrm{s}$ to $4.65 \pm 2.29 \mathrm{kPa} \cdot \mathrm{s}$ but again not significantly $(p=0.14)$. Although both iRaw and sRaw declined, there was no correlation between the parameters ( $\mathrm{r}=0.45$, not significant). A decreasing trend in FRC was observed after administration of budesonide/ formoterol indicating a reduction in hyperinflation.

The bronchodilating effect, defined as an increase in $\mathrm{i} V$ aw and a decrease in $\mathrm{i} R \mathrm{aw}$, seems higher in a limited number of patients $(n=7)$; this effect seems not to be systematic. This appears more clearly in the functional imaging parameters (table 2).

A sample size calculation revealed that in order to have a wellpowered study with $\mathrm{i} V$ aw as primary outcome parameter, a total of 16 patients would be required. When using iRaw, 34 patients were needed. Were FEV1 used as the primary endpoint, the number of required patients would go up to 93 . The least sensitive parameter in this regard is the PEF, with a total of 217 patients required to attain statistically significant results.

When considering the effect of placebo a significant decline in $\mathrm{i} V$ aw $(\mathrm{p}=0.025)$ and PEF $(\mathrm{p}=0.025)$ was observed. A downward trend was depicted by FEV1 $(\mathrm{p}=0.09)$. CFD-based resistance increased significantly $(p=0.005)$; body plethysmography showed a significant increase in $\mathrm{s}$ aw $(\mathrm{p}=0.026)$ and an upward trend in Raw $(p=0.07)$. Figure 3 illustrates the individual changes in $\mathrm{i} V$ aw and $\mathrm{i}$ Raw after the administration of the combination product and placebo.

A significant difference between placebo and the budesonide/ formoterol combination was observed in two lung function parameters: PEF $(p=0.027)$ and FEV1 $(p=0.037)$. The $s R a w$ also indicated a significant difference $(\mathrm{p}=0.036)$, as did TLC and FRC. The image-based peripheral airway volumes showed a highly significant difference between placebo and the active combination $(\mathrm{p}=0.0005)$ (table 3$)$.

Before unblinding, a prediction was made regarding the visit at which the active product was administered. The hypothesis was that after this visit the values must improve, where an improvement is defined as an increase in $\mathrm{i} V$ aw, FEV1, FEV1/ 
a) iVaw change baseline to placebo $\%$

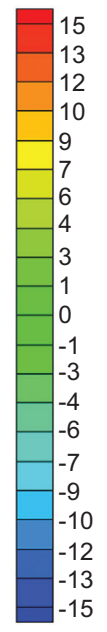

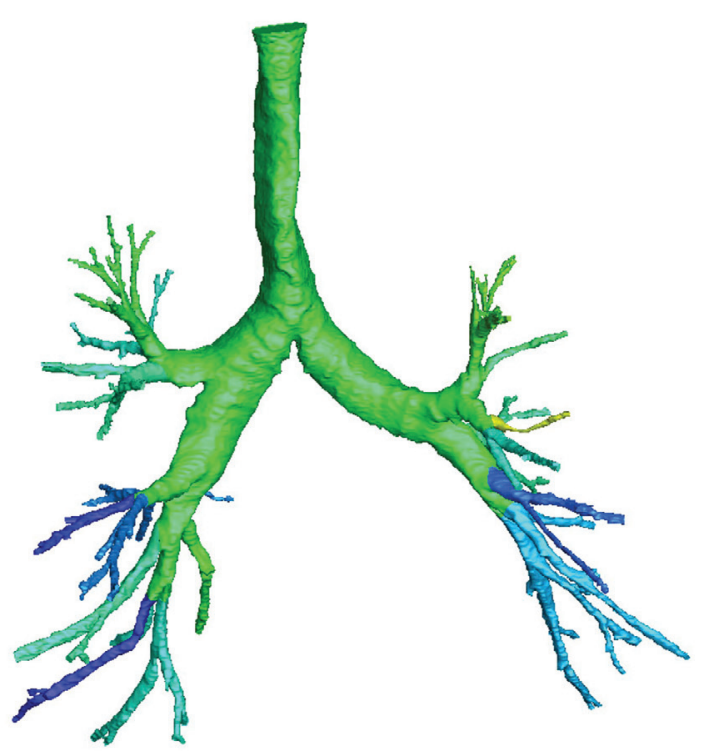

c) Raw change baseline to placebo $\%$
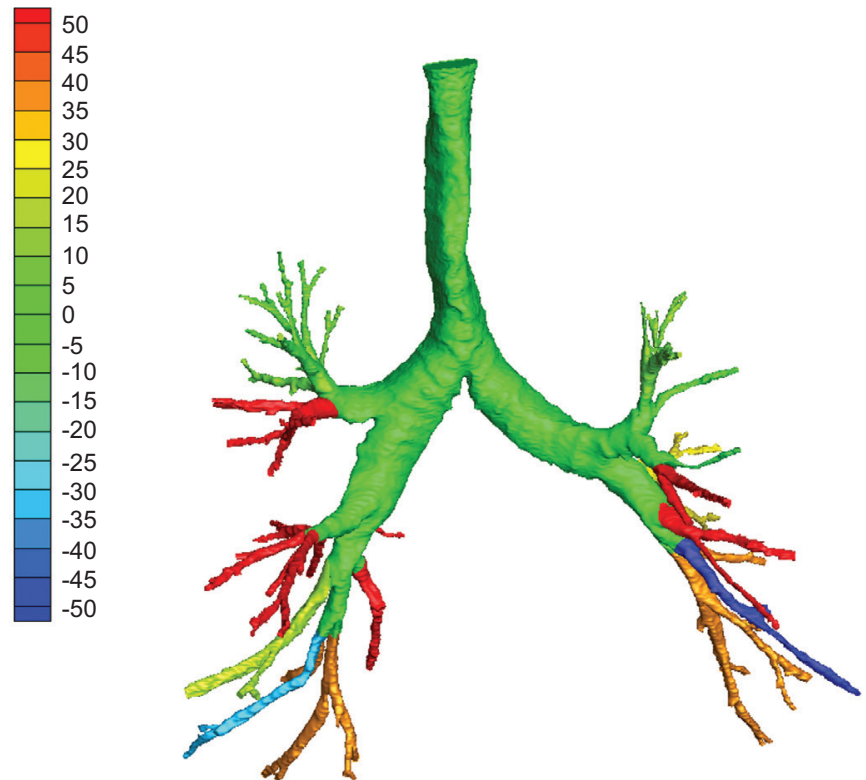

b) iVaw change baseline budesonide/formoterol \%

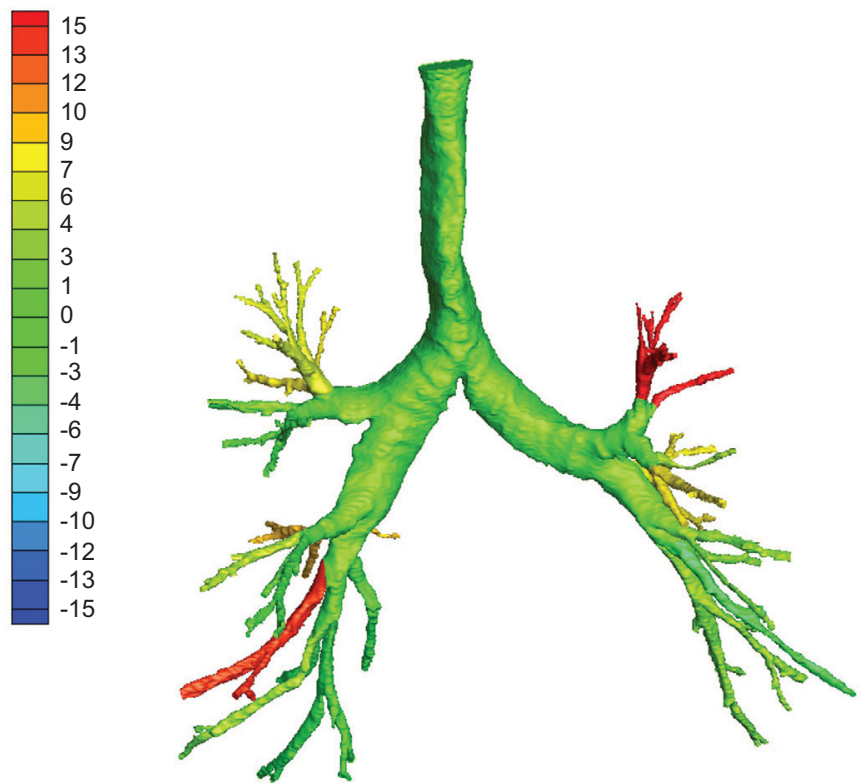

d) Raw change baseline to budesonide/formoterol \%

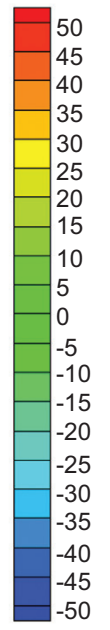

FIGURE 2. Illustration of a, b) distal airway volume (iVaw) and c, d) airway resistance (Raw) changes (\%) after administration of placebo (a, c) or budesonide/formoterol (b, d).

FVC and PEF and a decline in sRaw and Raw. Results showed that the FEV1 correctly predicted the visit at which budesonide/formoterol was administered in seven out of 10 cases (table 4). The FEV1/FVC was correct in only five out of 10 patients. Both PEF and Raw predicted eight out of 10 correctly and the sRaw nine out of 10 . The only parameter that in all cases adequately predicted the visit at which the active compound was administered was the iVaw (tables 5 and 6).

\section{DISCUSSION}

In this study we demonstrated that in severe COPD patients, after inhalation of fixed combinations, changes in image-based three-dimensional airway geometry can be detected that are not reflected in the spirometric data. The three-dimensional images clearly provide the possibility to assess the airway tree and the subsequent changes comprehensively. The traditional twodimensional approach is typically limited to a slice-by-slice assessment.

The severity of the disease is predominantly defined by FEV1, which is judged to be not completely reversible, and in fact barely reversible in stable stage III COPD patients [21-23]. Demonstrating an improvement is therefore inherently almost impossible and a COPD medication is then assessed based on its ability to slow down the decline in FEV1 [10]. The current study 


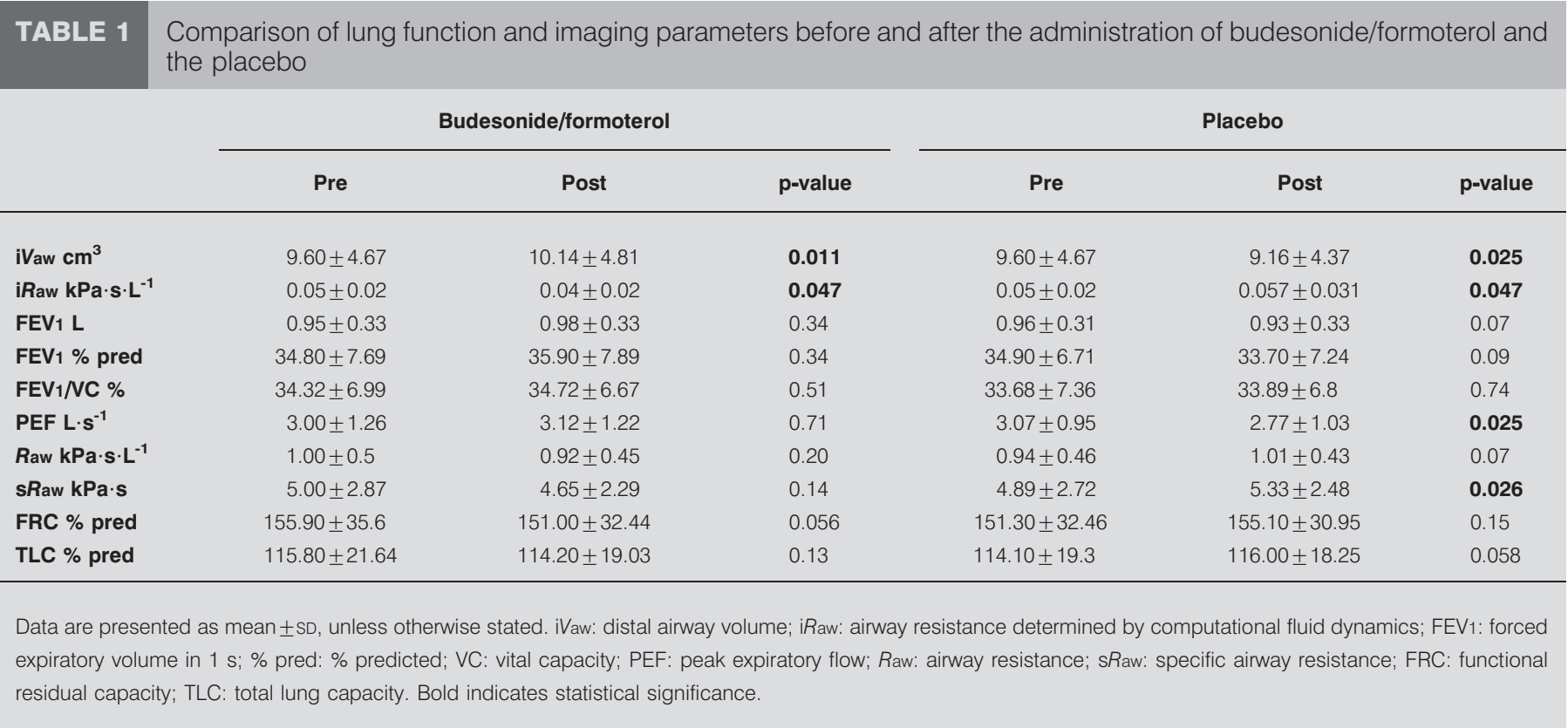

results confirmed this hypothesis, as only a minor, insignificant change in FEV1 is observed when patients are treated with budesonide/formoterol. At least a trend towards decline in FEV1 is seen in the placebo group. Airway volumes obtained using body plethysmography appear to be more sensitive and depict a declining trend in FRC in line with recent studies. The only parameters that describe a small but nonetheless significant improvement in the treated group and a significant decline in the placebo group are the $\mathrm{i} V$ aw and the $\mathrm{i}$ Raw.

The decline in iRaw goes along with a decline (although not statistically significant) in the Raw measured with body plethysmography. The absolute value of the Raw is much higher than the $\mathrm{i}$ Raw because $\mathrm{i}$ Raw does not take into account

\begin{tabular}{|c|c|c|}
\hline TABLE 2 & \multicolumn{2}{|c|}{$\begin{array}{l}\text { Average changes and standard deviations in } \\
\text { iVaw (distal airway volume) and iRaw (airway } \\
\text { resistance determined by computational fluid } \\
\text { dynamics) for all patients after administration of } \\
\text { budesonide/formoterol indicating the level of } \\
\text { inhomogeneity in bronchodilation }\end{array}$} \\
\hline Patient & $\Delta \mathrm{i} V_{a w} \%$ & $\Delta \mathrm{iRaw} \%$ \\
\hline 01 & $14.11 \pm 9.07$ & $-27.09 \pm 21.74$ \\
\hline 02 & $2.79 \pm 7.89$ & $8.24 \pm 49.17$ \\
\hline 03 & $-4.55 \pm 3.88$ & $24.83 \pm 53.04$ \\
\hline 04 & $6.21 \pm 5.03$ & $-11.67 \pm 36.77$ \\
\hline 05 & $-2.53 \pm 14.82$ & $51.02 \pm 118.36$ \\
\hline 06 & $19.52 \pm 27.85$ & $-34.71 \pm 43.05$ \\
\hline 07 & $17.40 \pm 26.14$ & $-19.57 \pm 40.66$ \\
\hline 08 & $5.36 \pm 10.87$ & $-9.21 \pm 37.27$ \\
\hline 09 & $35.38 \pm 134.81$ & $-6.48 \pm 39.89$ \\
\hline 10 & $13.24 \pm 10.82$ & $-38.45 \pm 20.81$ \\
\hline
\end{tabular}

Data are presented as mean $\pm \mathrm{SD}$
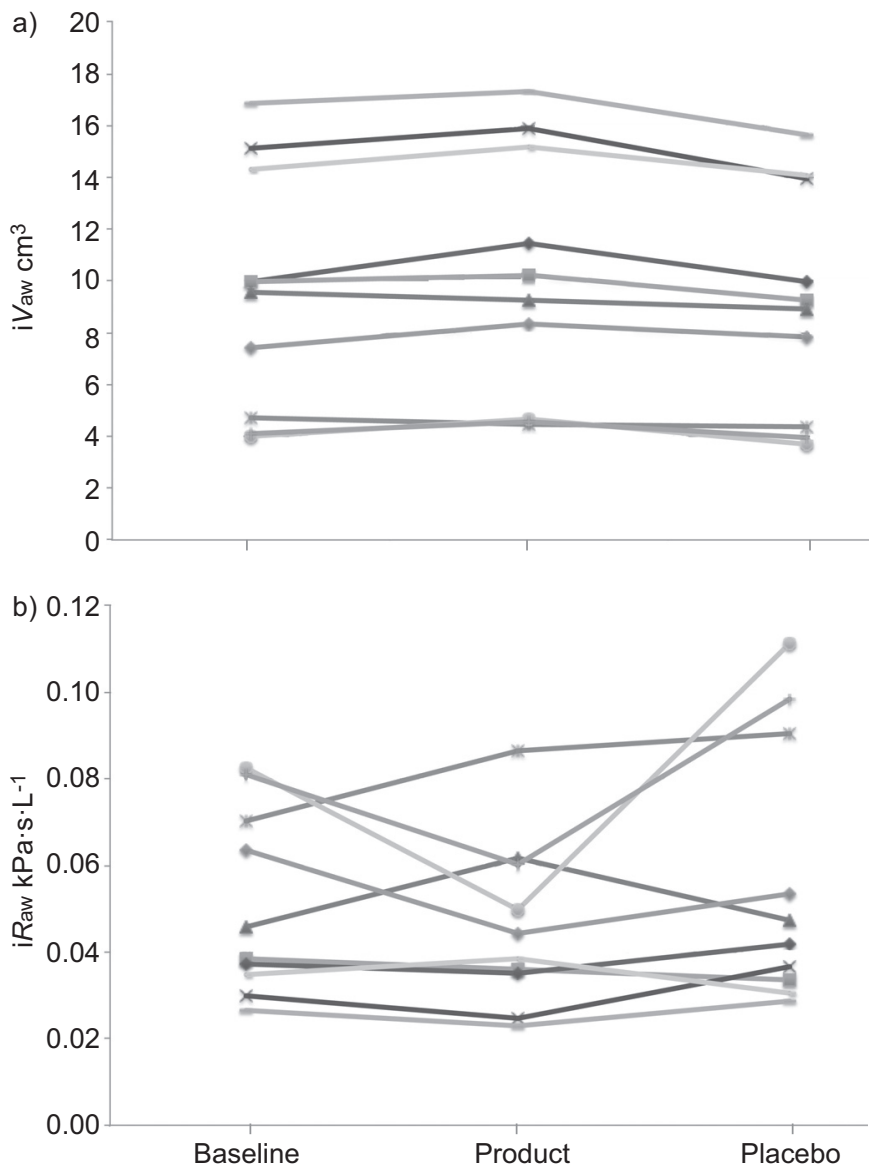

FIGURE 3. Individual changes in a) iVaw (distal airway volume) and b) iRaw (airway resistance determined by computational fluid dynamics) after administration of combination product and placebo. 


\begin{tabular}{|c|c|c|c|}
\hline \multirow{2}{*}{$\begin{array}{l}\text { TABLE } 3 \\
\text { Change \% }\end{array}$} & \multicolumn{3}{|c|}{$\begin{array}{l}\text { Comparison between the changes in lung } \\
\text { function and imaging parameters induced by } \\
\text { budesonide/formoterol and placebo }\end{array}$} \\
\hline & Budesonide/formoterol & Placebo & $p$-value \\
\hline iVaw & $+6.48 \pm 7.46$ & $-4.29 \pm 4.45$ & 0.0005 \\
\hline iRaw & $-7.02 \pm 23.72$ & $9.04 \pm 18.37$ & 0.005 \\
\hline $\mathrm{FEV}_{1}$ & $+3.56 \pm 10.49$ & $-3.63 \pm 6.1$ & 0.037 \\
\hline $\mathrm{FEV}_{1} / \mathrm{NC}$ & $+1.53 \pm 5.81$ & $+1.02 \pm 6.45$ & 0.87 \\
\hline PEF & $+4.47 \pm 20.2$ & $-10.26 \pm 12.89$ & 0.027 \\
\hline Raw & $-7.17 \pm 23.62$ & $+10.42 \pm 14.75$ & 0.09 \\
\hline sRaw & $-9.03 \pm 25.01$ & $+12.84 \pm 14.24$ & 0.036 \\
\hline FRC \% pred & $-4.9 \pm 7.06$ & $+3.8 \pm 7.67$ & 0.017 \\
\hline TLC \% pred & $-1.6 \pm 3.03$ & $+1.9 \pm 2.77$ & 0.015 \\
\hline \multicolumn{4}{|c|}{$\begin{array}{l}\text { Data are presented as mean } \pm \mathrm{SD} \text {, unless otherwise stated. iVaw: distal airway } \\
\text { volume; iRaw: airway resistance determined by computational fluid dynamics; } \\
\text { FEV1: forced expiratory volume in } 1 \mathrm{~s} \text {; VC: vital capacity; PEF: peak expiratory } \\
\text { flow; Raw: airway resistance; sRaw: specific airway resistance; FRC: functional } \\
\text { residual capacity; \% pred: \% predicted; TLC: total lung capacity. Bold indicates } \\
\text { significance. }\end{array}$} \\
\hline
\end{tabular}

the resistance of the upper airway and the equipment and illustrates the relative importance of upper airway resistance.

Furthermore, from this study it can be seen that when a COPD GOLD stage III patient doesn't receive active bronchodilating medication a relatively rapid decline in airway diameter and function occurs even after some hours, indicating also the role of the fixed combinations in maintaining airway patency in daily life. Therefore a highly significant difference is observed when comparing the treated and placebo groups.

The clinical relevance of these changes is the topic of ongoing research. In the current study the main question was to assess how different outcome parameters would describe changes induced by the inhalation product. It would appear valuable to first have outcome parameters that accurately describe changes in airway structure and function induced by a product. In a

\begin{tabular}{|c|c|c|c|c|}
\hline \multirow{2}{*}{$\begin{array}{l}\text { TABLE } 4 \\
\text { Patient }\end{array}$} & \multicolumn{4}{|c|}{$\begin{array}{l}\text { Predictive value of the change in forced } \\
\text { expiratory volume in } 1 \mathrm{~s}(\mathrm{FEV} 1) \text { to determine the } \\
\text { visit }(\mathrm{V}) \text { at which budesonide/formoterol was } \\
\text { administered }\end{array}$} \\
\hline & $\Delta$ FEV1 V2 L & $\triangle F E V_{1} V_{3} L$ & Product & Unblind \\
\hline 01 & -0.069 & 0.081 & V3 & V3 \\
\hline 02 & -0.02 & 0 & V3 & V2 \\
\hline 03 & -0.02 & 0.041 & V3 & V3 \\
\hline 04 & 0.029 & -0.1 & V2 & V2 \\
\hline 05 & -0.099 & -0.11 & V2 & V2 \\
\hline 06 & -0.041 & 0.19 & V3 & V3 \\
\hline 07 & 0.02 & 0.01 & V2 & V2 \\
\hline 08 & -0.041 & -0.05 & V2 & V3 \\
\hline 09 & -0.021 & 0.03 & V3 & V2 \\
\hline 10 & 0.09 & 0.02 & V2 & V2 \\
\hline
\end{tabular}

\begin{tabular}{|c|c|c|c|c|}
\hline \multirow{2}{*}{$\begin{array}{l}\text { TABLE } 5 \\
\text { Patient }\end{array}$} & \multicolumn{4}{|c|}{$\begin{array}{l}\text { Predictive value of the change in distal airway } \\
\text { volume (iVaw) to determine the visit }(V) \text { where } \\
\text { budesonide/formoterol was administered }\end{array}$} \\
\hline & $\Delta \mathrm{iVaw}$ V2 $\mathrm{cm}^{3}$ & $\Delta$ iVaw V3 $\mathrm{cm}^{3}$ & Product & Unblind \\
\hline 01 & -0.25 & 14.45 & V3 & V3 \\
\hline 02 & 2.19 & -7.32 & V2 & V2 \\
\hline 03 & -6.87 & -3.11 & V3 & V3 \\
\hline 04 & 5.16 & -7.87 & V2 & V2 \\
\hline 05 & -4.59 & -6.88 & V2 & V2 \\
\hline 06 & -7.27 & 17.23 & V3 & V3 \\
\hline 07 & 11.87 & -3.34 & V2 & V2 \\
\hline 08 & -1.56 & 6.09 & V3 & V3 \\
\hline 09 & 2.55 & -7.25 & V2 & V2 \\
\hline 10 & 12.97 & 5.74 & V2 & V2 \\
\hline
\end{tabular}

second phase, the clinical relevance of these changes could be investigated by correlating them to, for example, patientreported outcome parameters (PROs). After all, if a parameter is not sensitive enough to reliably pick up changes in the system following a treatment, what would be the value of correlating this parameter with PROs? Should a correlation exist, this would still not mean that the product caused this change in PRO. Of course it is important to assess these PROs, as diminishing respiratory symptoms should be one of the goals of treating COPD. As we can see that some patients have a more pronounced response to budesonide/formoterol than others, it is interesting to know whether they also report less dyspnoea.

The double-blind protocol in this study offered an interesting possibility to assess how well the different parameters could distinguish between the placebo visit and the visit where the active product was administered. The image-based parameters appeared to be the only parameters that correctly identified the respective visits for all patients. The FEV1/FVC ratio performed the worst, followed by the FEV1.

Even though this trial was performed in a limited number of patients, the placebo-controlled, crossover design ensured a

TABLE 6 Predictive value of the change in airway resistance determined by computational fluid dynamics (iRaw) to determine the visit (V) where budesonide/formoterol was administered

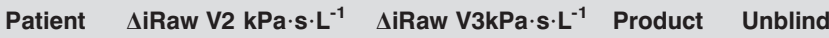

\begin{tabular}{lcccc}
\hline 01 & -0.98 & -19.46 & V3 & V3 \\
02 & -0.86 & 23.10 & V2 & V2 \\
03 & 59.41 & 12.47 & V3 & V3 \\
04 & -18.94 & 34.23 & V2 & V2 \\
05 & 35.18 & 41.80 & V2 & V2 \\
06 & -43.74 & 49.05 & V3 & V3 \\
07 & -32.42 & 29.69 & V2 & V2 \\
08 & 9.95 & -16.25 & V3 & V3 \\
09 & -14.94 & 11.34 & V2 & V2 \\
10 & -42.81 & -18.93 & V2 & V2 \\
\hline
\end{tabular}


good power of this pilot study. Based on these results it could be hypothesised that imaging, or at least a combination of lung function tests and imaging, is better suited to describe the mode of action of a product. The sample size calculations that were based on these data and performed post hoc indicated that imaging parameters could significantly reduce the number of patients in clinical trials by providing more sensitive information on the mode of action of a product. This opens the possibility of using this method at an early clinical stage to compare different compounds to each other or to placebo. Also dose-response based on imaging parameters in a limited number of patients could yield a more compelling picture versus the FEV1 response to different doses in very large clinical trials where results are often ambiguous.

In previous large-scale studies using FEV1 as an end-point, it can be observed that inhaled therapy with the recommended fixed combinations improves FEV1 in absolute terms only to a limited extent and that the decline in FEV1 is not altered. But at the same time other end-points such as quality of life or even, in larger populations, mortality, show at least a trend to improvement [10, 24-26]. This suggests that FEV1 may underscore real changes in airway structure induced by inhalation of combination therapies.

At present fixed combinations are most frequently and often uniquely used in severe stage III COPD patients and are considered to be mainly symptomatic treatments with the aim to improve daily life symptoms and exacerbations, but not, or to a limited extent, the progression of the disease. We therefore chose a combination product in this study to see whether the widely used (mainly for symptomatic improvement) fixed combinations do have an influence on the airway geometry in severe stage III COPD patients. The aim was not only to understand and to see the sensitivity of the FEV1 but also to better understand the discrepancies between some PROs and FEV1 with the fixed combinations. Therefore insight both into the mode of action and also into the clinical relevance of the fixed combination inhalation therapy mostly used and recommended could be obtained. For this aim, a small-scale study seemed to be indicated given that the mentioned discrepancies between PROs and FEV1 were already demonstrated in previous large-scale and long-term studies (Tristan, Torch, Euroscope, Uplift).

Treatment is mainly targeted at reducing the work of breathing in COPD patients. From physiological and anatomical studies $[27,28]$ it is known that the majority of the airway resistance is situated in the first 4-6 generations. It is therefore not unreasonable to assume that airway dilation in this region results in a clinical improvement in the patient's condition. It would be worthwhile to assess the respiratory structure and function in a broader range of disease severity levels in a larger set of patients. One could for instance take lung function tests and MSCT images during an episode of exacerbation and after recovery. This would allow for a correlation between imaging parameters, lung function and patient-reported outcome parameters.

Even though the functional-imaging method appears to provide sensitive and valuable information, the technique also has its limitations. Segmentation still involves some manual processing of the images, potentially introducing a level of variability. Airways smaller than 1-2 mm are not visible with the current state-of-the-art CT scanners and therefore cannot be segmented. The cost and the use of ionising radiation currently prevents the implementation of the method in very large phase-III trials and as a standard test in clinical routine for all patients. It appears that this method is best suited to determine product efficacy in early clinical phases and to assess treatment of the more severe patients in a clinical routine setting. As such the method could complement other novel pulmonary function tests such as multi-breath nitrogen washout and forced oscillation which are targeted at obtaining more information about the smaller airways. These methods are in general less expensive and provide information about the tissue and the smaller airways. However they do not provide regional information and are sometimes labour intensive. Therefore a proper combination of imaging and lung function tests could result in an efficient, comprehensive set of tools to treat patients with respiratory diseases.

\section{CLINICAL TRIALS}

This study is registered at EudraCT, with identifier number EudraCT 2009-016502-16, PML_DOC_0905_/_ISSSYmB0020.

\section{STATEMENT OF INTEREST}

Statements of interest for J. de Backer and W. de Backer can be found at www.erj.ersjournals.com/site/misc/statements.xhtml

\section{REFERENCES}

1 Tashkin DP, Celli B, Decramer M, et al. Bronchodilator responsiveness in patients with COPD. Eur Respir J 2008; 31: 742-750.

2 Calverley PM, Burge PS, Spencer S, et al. Bronchodilator reversibility testing in chronic obstructive pulmonary disease. Thorax 2003; 58: 659-664.

3 Pauwels RA, Buist AS, Calverley PM, et al. Global strategy for the diagnosis, management, and prevention of chronic obstructive pulmonary disease. NHLBI/WHO Global Initiative for Chronic Obstructive Lung Disease (GOLD) Workshop summary. Am J Respir Crit Care Med 2001; 163: 1256-1276.

4 Jones PW, Quirk FH, Baveystock CM. The St George's Respiratory Questionnaire. Respir Med 1991; 85: Suppl. B, 25-31.

5 Jones PW, Bosh TK. Quality of life changes in COPD patients treated with salmeterol. Am J Respir Crit Care Med 1997; 155: 1283-1289.

6 Jones PW. COPD: functional status, health status and primary care. Prim Care Respir J 2011; 20: 227-228.

7 Jones PW, Anderson JA, Calverley PM, et al. Health status in the TORCH study of COPD: treatment efficacy and other determinants of change. Respir Res 2011; 12: 71.

8 Hurst JR, Vestbo J, Anzueto A, et al. Susceptibility to exacerbation in chronic obstructive pulmonary disease. N Engl J Med 2010; 363: 1128-1138.

9 Adams CP, Brantner VV. Spending on new drug development. Health Econ 2010; 19: 130-141.

10 Calverley PM, Anderson JA, Celli B, et al. Salmeterol and fluticasone propionate and survival in chronic obstructive pulmonary disease. N Engl J Med 2007; 356: 775-789.

11 Calverley P, Pauwels R, Vestbo J, et al. Combined salmeterol and fluticasone in the treatment of chronic obstructive pulmonary disease: a randomised controlled trial. Lancet 2003; 361: 449-456.

12 Burge PS, Calverley PM, Jones PW, et al. Randomised, double blind, placebo controlled study of fluticasone propionate in patients with moderate to severe chronic obstructive pulmonary disease: the ISOLDE trial. BMJ 2000; 320: 1297-1303.

13 Mannino DM. COPD: epidemiology, prevalence, morbidity and mortality, and disease heterogeneity. Chest 2002; 121: Suppl. 5, 121S-126S.

14 Haruna A, Muro S, Nakano Y, et al. CT scan findings of emphysema predict mortality in COPD. Chest 2010; 138: 635-640. 
15 Mair G, Maclay J, Miller JJ, et al. Airway dimensions in COPD: relationships with clinical variables. Respir Med 2010; 104: 1683-1690.

16 Diaz AA, Valim C, Yamashiro T, et al. Airway count and emphysema assessed by chest $\mathrm{CT}$ imaging predicts clinical outcome in smokers. Chest 2010; 138: 880-887.

17 Lin CL, Tawhai MH, McLennan G, et al. Computational fluid dynamics. IEEE Eng Med Biol Mag 2009; 28: 25-33.

18 De Backer JW, Vos WG, Gorle CD, et al. Flow analyses in the lower airways: patient-specific model and boundary conditions. Med Eng Phys 2008; 30: 872-879.

19 De Backer JW, Vos WG, Vinchurkar SC, et al. Validation of computational fluid dynamics in CT-based airway models with SPECT/CT. Radiology 2010; 257: 854-862.

20 Backer JW, Vos WG, Devolder A, et al. Computational fluid dynamics can detect changes in airway resistance in asthmatics after acute bronchodilation. J Biomech 2008; 41: 106-113.

21 Appleton S, Poole $\mathrm{P}, \mathrm{Smith} B$, et al. Long-acting $\beta_{2}$-agonists for poorly reversible chronic obstructive pulmonary disease. Cochrane Database Syst Rev 2006; 3: CD001104.
22 Sin BA, Akkoca O, Saryal S, et al. Differences between asthma and COPD in the elderly. J Investig Allergol Clin Immunol 2006; 16: 44-50.

23 Donohue JF. Minimal clinically important differences in COPD lung function. COPD 2005; 2: 111-124.

24 Calverley PM, Rabe KF, Goehring UM, et al. Roflumilast in symptomatic chronic obstructive pulmonary disease: two randomised clinical trials. Lancet 2009; 374: 685-694.

25 Tashkin DP, Celli B, Senn S, et al. A 4-year trial of tiotropium in chronic obstructive pulmonary disease. N Engl J Med 2008; 359: 1543-1554.

26 Bale G, Martinez-Camblor P, Burge PS, et al. Long-term mortality follow-up of the ISOLDE participants: causes of death during 13 years after trial completion. Respir Med 2008; 102: 1468-1472.

27 Calverley PM, Koulouris NG. Flow limitation and dynamic hyperinflation: key concepts in modern respiratory physiology. Eur Respir J 2005; 25: 186-199.

28 Yang XL, Liu Y, Luo HY. Respiratory flow in obstructed airways. J Biomech 2006; 39: 2743-2751. 